\title{
REPRESENTAÇÃO DO TRANSPORTE DE CARGAS NA FERROVIA DE INTEGRAÇÃO OESTE LESTE COM O EMPREGO DE SIMULAÇÃO E HEURÍSTICA
}

\author{
Jorge Ubirajara Pedreira Júnior \\ Universidade Federal da Bahia (UFBA) \\ jorgesars@gmail.com \\ Ademar Nogueira do Nascimento \\ Universidade Federal da Bahia (UFBA) \\ annas@ufba.br
}

\begin{abstract}
Resumo
A representação do tráfego de trens em estudos de simulação é uma tarefa complexa, que exige conhecimentos específicos das operações ferroviárias. De fato, diversos conflitos de cruzamento que são resolvidos diariamente pelos centros de controle tráfego devem ser incorporados ao modelo para torná-lo válido. Assim sendo, consistentes procedimentos de modelagem de sistemas ferroviários foram analisados através do estado da arte com o objetivo de construir um modelo adequado para simular o transporte de minério de ferro na Ferrovia de Integração Oeste Leste (FIOL), que está sendo construída nos estados da Bahia e do Tocantins. Vale salientar que os limites da modelagem estão compreendidos entre o carregamento de minério no município de Caetité (BA) e o seu descarregamento na futura área portuária (Porto $\mathrm{Sul}$ ), que está sendo construída no município de Ilhéus (BA). O método utilizado é uma regra heurística para resolução de conflitos de trens embutida em um modelo de simulação de eventos discretos no software Arena ${ }^{\circledR}$. Posteriormente a qualidade do modelo foi testada observando a eficiência da heurística, comparando-se os parâmetros operacionais planejados do projeto com as saídas geradas pelo modelo desenvolvido. Espera-se, desta forma, contribuir para o eficiente desempenho logístico da FIOL.

Palavras-Chaves: Simulação; Heurística; Transporte Ferroviário.
\end{abstract}

\begin{abstract}
Train traffic representation in simulation tools is a complex task that demands specific knowledge regarding rail operations. In fact, many traffic control centers solve crossing conflicts in a daily basis and this routine must be inserted in the model to make it valid. Given this, this work aims to extract good practices in modeling railroad systems from the state of art in order to develop an appropriate model to simulate the iron ore transportation in Ferrovia de Integração Oeste Leste (FIOL) railway, being built in the states of Bahia and Tocantins, Brazil. It is worth mentioning that the model scope is limited within the loading process in the town of Caetite (BA) and the port area (Porto Sul) in the town of Ilhéus (BA), which is also under construction. The methodology approach is a local-decision heuristic embedded in a discrete-event simulation in Arena ${ }^{\circledR}$ software. Afterwards, the model quality is tested considering the heuristic efficiency and comparing the outputs resulted from the model with the operational parameters of the project. Thus, one expects to contribute to an efficient logistics performance of FIOL railway.
\end{abstract}

Keywords: $\quad$ Simulation; Heuristics; Railroad Transportation. 


\section{INTRODUÇÃO}

$\mathrm{O}$ atual cenário da infraestrutura brasileira dificulta enormemente o desenvolvimento do país. De acordo com o documento The Global Competitiveness Report 2013-2014 (World Economic Forum, 2013), o Brasil ocupa a $71^{\mathrm{a}}$ posição dentre 148 países, na categoria infraestrutura do índice de competitividade global. O documento ainda relata que a oferta de infraestrutura inadequada é identificada como o impedimento mais sério para se fazer negócios dentro de uma lista de outros problemas que incluem carga tributária, burocracia governamental ineficiente e regulações trabalhistas restritivas.

A composição da matriz de transportes brasileira, concentradamente rodoviária, pode ser uma das principais razões deste ineficiente cenário, sendo consequência de inadequadas e sucessivas políticas de governo ao longo do século XX. Isso porque esse modal de transporte é inapropriado para uso em longas distâncias e cargas muito pesadas e, logo, indesejável para um país de dimensões continentais e exportador de commodities, a exemplo de minério de ferro e soja, como o Brasil.

Em razão desta situação crítica, uma série de investimentos do governo federal estão sendo planejados, principalmente a construção, ampliação e melhoria de portos e ferrovias. Um importante componente nesse contexto é a construção da Ferrovia de Integração Oeste Leste (FIOL), prevista para interligar os municípios de Ilhéus (BA) e Figueirópolis (TO), onde haverá o intercâmbio com outro importante empreendimento, a Ferrovia Norte Sul. O principal objetivo da FIOL é transportar cargas de minério ferro, grãos e farelo de soja para o Porto Sul (Ilhéus, BA), em fase final de licenciamento, de onde seguem para o mercado internacional. Nesse contexto, a proposta do presente artigo é avaliar as condições operacionais do transporte de minério de ferro pela FIOL, cujo traçado pode ser observado na Figura 1.

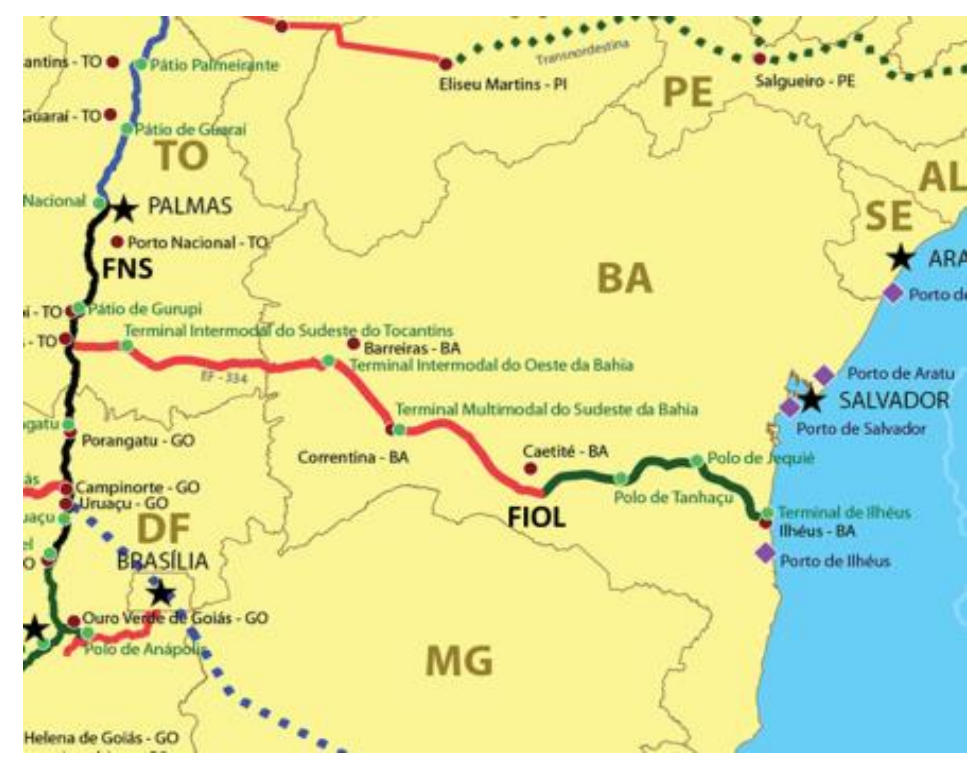

Figura 1 - Traçado da FIOL entre a Ferrovia Norte-Sul e o Porto Sul Fonte: BRASIL, 2010

Estima-se (BRASIL, 2010) que cerca de $70 \%$ da receita operacional da malha no início da operação terá origem no transporte de minério de ferro, entre as cidades de Caetité e Ilhéus, no estado da Bahia. Devido a esta relevância econômica, o minério de ferro é a principal motivação para a construção desta ferrovia.

O Brasil e outros países exportadores desse tipo de produto se beneficiaram bastante do "Superciclo de Commodities" iniciado nos anos 2000, que representou uma fase de grande ascensão nos preços desses tipos de mercadorias. Essa subida aconteceu principalmente 
devido ao crescimento na demanda de muitos mercados emergentes (especialmente, China) que resultou em uma balança comercial positiva para muitos países exportadores de commodities. A Figura 2, obtida da base de dados do Index Mundi (2015), demonstra o aumento considerável do preço do minério de ferro, saindo de US\$12,45/tonelada base seca, em 2001, para US\$ 187,18/tonelada base seca, em 2011.

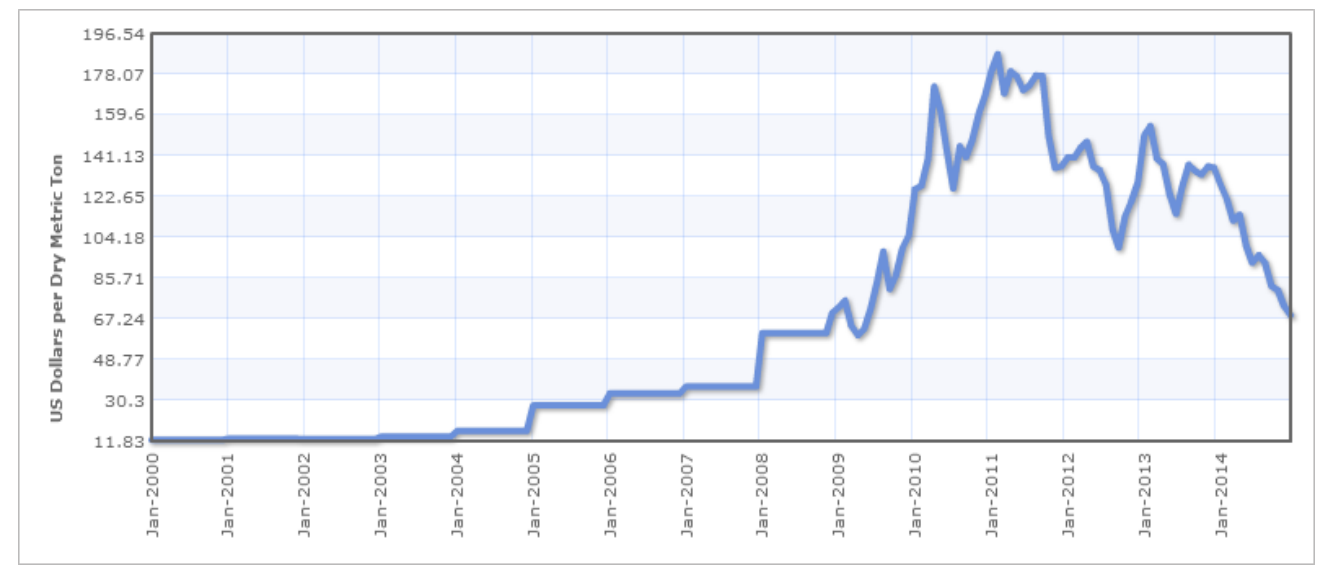

Figura 2 - Preço do minério de ferro por toneladas em base seca (jan/2000 a dez/2014) Fonte: Index Mundi (2015)

Não obstante esse cenário favorável na década passada, o cenário recente não é o mais otimista para as pequenos e médias mineradoras. De fato, o preço do minério de ferro tem caído significativamente desde 2011 e, somente em 2014, experimentou uma queda de cerca de 50\% em seu valor (de US\$ 135,79, em 2001, para US\$ 68,80, por tonelada em base seca). De acordo com informações publicadas por NG (2014), o grupo empresarial multinacional Goldman Sachs apontou em relatório que a "Era do Ferro" deveria acabar em 2014 ao passo que nova capacidade produtiva finalmente alcançou o crescimento da demanda e os lucros marginais começarão sua reversão para a média histórica. Ainda segundo esse relatório, somente as indústrias capazes de produzir em larga escala e com logística eficiente sobreviverão a esse processo.

Devido a essa delicada situação econômica, a FIOL poderá representar um papel importante na mitigação desse risco iminente para o cenário da mineração de ferro na Bahia. Estudos endossam esse fato, indicando que o transporte ferroviário é capaz de produzir economias de até $60 \%$ quando comparados ao transporte rodoviário (CNT, 2006). Isso ocorre principalmente em função das características vantajosas do transporte ferroviário, como maior peso transportado e maior eficiência energética (menor uso de combustível para transportar uma mesma carga), além de apresentar uma vida útil dos equipamentos mais longa.

Apesar da viabilidade do projeto já ter sido atestada em estudos preliminares (VALEC, 2010), em um futuro próximo quando novos operadores pleitearem a utilização de capacidade da ferrovia, alguns desafios se tornarão mais evidentes. Este fato está relacionado com o principal gargalo de um projeto ferroviário de linha singela (linha única), onde somente um trem pode utilizar a linha principal, enquanto os outros aguardam a sua passagem em linhas desviadas localizadas em alguns pontos longo da malha, com o propósito de realizar cruzamentos de trens em sentidos inversos. Estudos conduzidos pela VALEC (BRASIL, 2010), empresa responsável pela construção da ferrovia, mostraram que após os primeiros 5 anos de operação a capacidade de transporte ferroviária estará comprometida, devido ao aumento do número de cruzamentos de trens realizados que conduzirão a um atraso do tempo de trânsito entre origem e o destino das composições ferroviárias (conjunto locomotiva e vagões). Caso isto se consolide, custos associados à espera de trens em filas e atrasos 
causados por navios aguardando por carregamento (demurrage) se tornarão mais prováveis de acontecerem.

Com o objetivo de contribuir para a análise de viabilidade técnica deste empreendimento, este artigo apresenta a primeira parte de um trabalho que pretende analisar a performance logística de todo o sistema de transporte na FIOL. Nesse sentido, considerandose que o sistema ferroviário, em geral, possui algumas especificidades em relação ao movimento dos trens, uma heurística de decisão local foi desenvolvida para resolver os conflitos que podem aparecer ao longo dos seus itinerários. Esta é uma parte compulsória do trabalho que necessita ser implementada no modelo para torná-lo uma representação válida de um sistema ferroviário. Para atender a esse objetivo principal, essa heurística foi desenvolvida na software de simulação Arena ${ }^{\circledR}$, visando representar o sistema a fim de obter variáveis de saída de interesse para os planejadores do tráfego ferroviário.

\section{A MOVIMENTAÇÃO DE TRENS EM UMA MALHA FERROVIÁRIA}

\subsection{OS CONFLITOS DE TRENS EM LiNHA Singela}

A maneira específica como os trens se movem na malha é determinada pela morfologia de um sistema ferroviário. Sendo assim, é importante analisar as operações do mesmo, principalmente no contexto dos conflitos dos trens pelo uso das vias em linha singela. A Figura 3 ilustra uma colisão iminente entre trens se movendo em sentidos contrários. Pelo processo descrito, os trens A e B concorrem por uma mesma linha para realizarem seus deslocamentos (a). Neste exemplo, o trem A precisaria acessar uma linha desviada no pátio logo à frente (b), aguardar para que o trem B possa percorrer o caminho (c), liberando a linha principal para que ele possa continuar a sua trajetória $(\mathrm{d})$.

a)

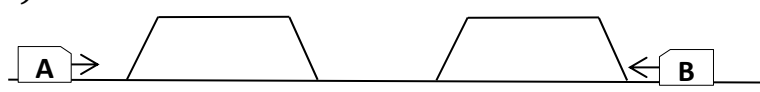

c)

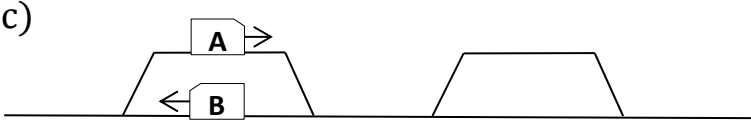

b)

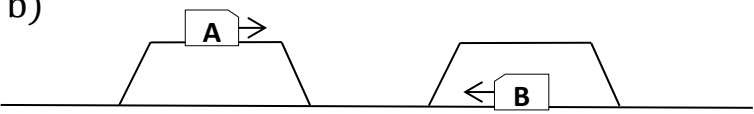

d)

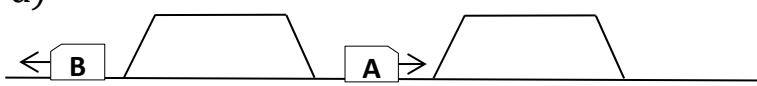

Figura 3 - Ilustração da operação para evitar a colisão frontal de trens

Neste ponto, é importante mencionar que a ferrovia em estudo (FIOL) funcionará em um sistema de sinalização baseado em bloqueio fixo (sessões de bloqueio ou SB). Isso significa que somente um trem por vez poderá ocupar cada SB e caso outro trem deseje ocupar essa mesma SB e se mover ao longo dela, só poderá fazê-lo quando o trem anterior a tiver liberado (deixado de trafegar ao longo dessa SB). A Figura 4, a seguir, demonstra este sistema de sinalização nos pátios 1 e 2 e o segmento de linha que os conecta. Observa-se que existirão 2 SB's em cada seção de linha entre pátios e cada linha em um pátio (principal e desviada) representa uma SB.

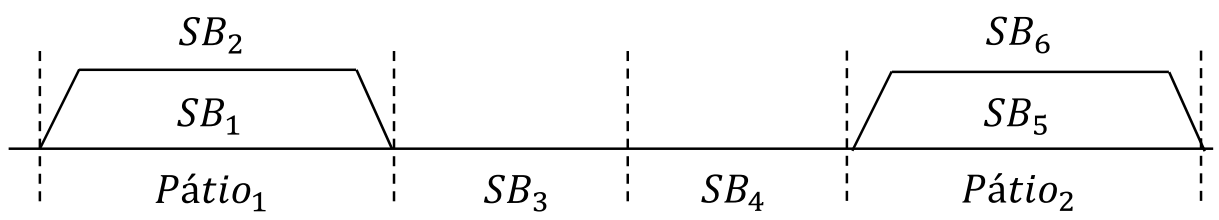

Figura 4 - Sistema de sinalização em bloqueio fixo adotado pela FIOL

A simples solução descrita na Figura 3 tende a ficar mais complicada quando o número de trens em ambas as direções aumenta em um sistema de bloqueio fixo. O pior caso acontece quando dois pares de trens, movendo-se em sentidos contrários se aproximam de 
uma situação de conflito. Desse momento em diante, um conjunto de restrições mais rígidas deve ser atendida por cada trem para a decisão de esperar ou mover-se adiante. Quando o processo de decisão para resolver este tipo de conflito não está bem amarrado, uma situação de travamento acontece, impedindo que cada trem possa prosseguir em seu percurso, como indicado na Figura 5.

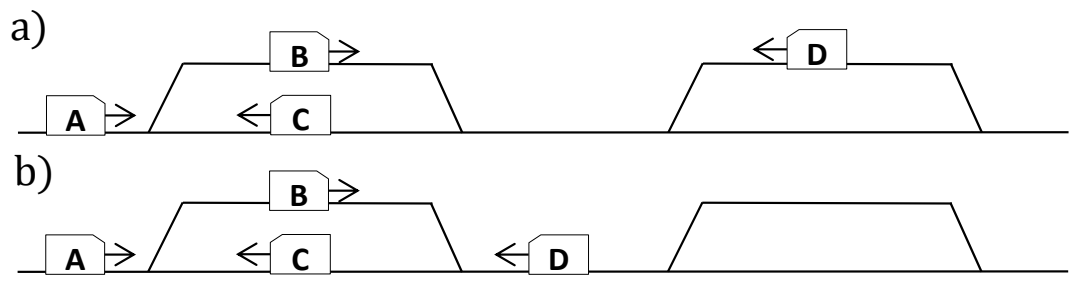

Figura 5 - Trens em uma situação de travamento

A circunstância apresentada acima demonstra como uma decisão desacertada tomada pelo trem D (mover-se adiante) resulta em uma situação de travamento. Neste caso, nenhum dos trens pode tomar a decisão de mover-se adiante, devido à existência de uma SB ocupada logo à frende de cada um. Para reorganizar o fluxo, os trens A ou D precisam retornar para o pátio anterior às suas atuais posições, uma operação que consome bastante tempo, promovendo atrasos no fluxo geral da malha. Portanto, um planejamento rigoroso para operação da linha deve ser estabelecido para que inconsistências não ocorram.

\subsection{ABORDAGEM TEÓRICA DO PROBLEMA}

Os problemas de resolução de conflitos em circulação de trens estão especialmente relacionados com o processo de programação dos itinerários em um sistema ferroviário. Ao longo de seus trajetos, as composições concorrem pela utilização de linhas (principais, desviadas, de atividades), recursos humanos (maquinistas, equipes de manutenção) e recursos físicos (silos para carregamento, postos de abastecimento, viradores de vagões). Dentro deste contexto, o operador ferroviário deve atender às expectativas do cliente quanto ao tempo de entrega das mercadorias e, ao mesmo tempo, evitar a sobreposição no uso destes recursos. Para lidar com esses objetivos conflitantes, especialistas programam diariamente os percursos de cada trem em diferentes regiões da malha em um gráfico temporal. Desta forma, os trens ao atingirem as regiões de pátios de cruzamento, permanecem estacionados (linhas paralelas em relação ao eixo do tempo), permitindo a passagem de outro trem no sentido contrário, conforme pode ser observado na Figura 6.

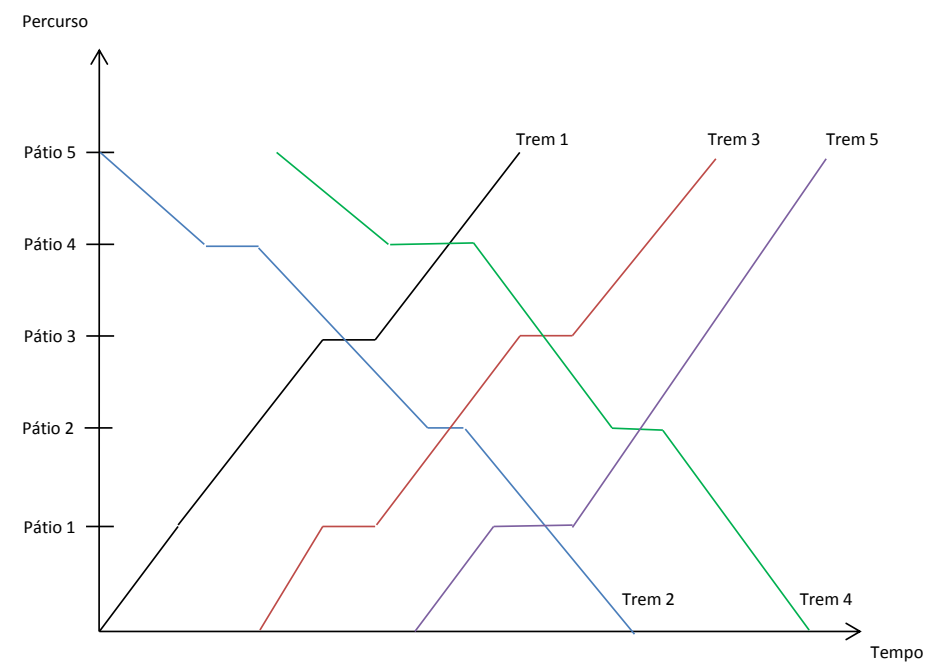

Figura 6 - Diagrama da programação diária de trens 
Uma caraterística bastante peculiar deste tipo de problema é o seu comportamento dinâmico, no qual o estado de variáveis de interesse ("posição", por exemplo, como no gráfico da Figura 6) se altera com decorrer do tempo. Neste sentido, o paradigma da Simulação Computacional é uma abordagem bastante indicada para tratar esse tipo de problema, uma vez que se trata da representação de sistemas que evoluem com o tempo. Dentro desse contexto, a Simulação de Eventos Discretos (SED) tem sido a especialmente empregada, onde o estado destas variáveis permanece constante ao longo tempo, mudando somente em pontos específicos e bem definidos chamados eventos (Banks, 1998). Muitos sistemas de filas, onde as variáveis a serem mensuradas são quantidade de clientes/produtos em espera (ou em serviço) são avaliadas através da SED.

Muitas vantagens podem ser obtidas quando este método é utilizado segundo Sokolowski e Banks (2009). Em primeiro lugar, a capacidade de diagnóstico do problema é aumentada, uma vez que as interações entre as variáveis podem ser analisadas em muitos sistemas complexos. Outro aspecto importante é a exploração das possibilidades sem intereferir no sistema real, através da avaliação de diferentes procedimentos operacionais. Como consequência deste último, aumenta-se a probabilidade de investimentos de forma mais racional, uma vez que simular o sistema custa menos que alterá-lo.

Com frequência, aplicações de SED vêm acompanhadas de outras técnicas visando otimização operacional, conferindo ao resultado final um forte poder de representação do sistema mesclado com melhorias proporcionadas pelas soluções apresentadas nos algoritmos. Vale destacar a importância de algumas contribuições destas aplicações no cenário ferroviário, tanto no contexto internacional quanto no nacional.

\subsection{ESTADO DA ARTE EM REPRESENTAÇÃo de TráFEgo FERROVIÁRIO}

Sabe-se que, por vezes, a programação diária realizada pelos especialistas é prejudicada por perturbações que ocorrem ao longo da operação, a exemplo de condições ambientais adversas, falhas de equipamentos e acidentes. Para enfrentar esse tipo de situação onde os profissionais da central de tráfego devem reprogramar com rapidez a circulação, Cheng (1998) desenvolveu um modelo híbrido combinando SED e simulação em redes em um sistema ferroviário de fluxo intenso. A ideia principal foi aproveitar os benefícios e mitigar as deficiências de cada método para construir um algoritmo aplicável à rotina dos planejadores de tráfego.

Apesar da SED ser um método tradicional para lidar com sistemas dinâmicos, resolver problemas de confito de trens durante a simulação pode tornar o tempo de processamento proibitivo. Em contrapartida, apesar da simulação em redes não tratar os problemas de forma dinâmica, esta pode resolver rapidamente os conflitos em potencial. Isso é possível através de algoritmos de otimização em grafos (redes de nós ligados por arcos) que calculam o caminho mais longo numa ordem topológica. Esta ordem consiste no ranqueamento dos nós em uma lista de prioridades que, neste caso, é descrita pela sequência que os trens devem obedecer. Dessa forma, Cheng realizou a hibridização dos métodos substituindo a ordem topológica por uma ordem temporal através das partidas e chegadas permitidos pelas dependências de cada nó. Por fim, alguns experimentos foram executados, permitindo concluir que o método proposto se mostrou mais eficiente e flexível do que a simulação em redes, retendo as vantagens de um modelo em SED.

Frequentemente, muitas representações ignoram aspectos de dinâmica ferroviária (movimento de trens) que influenciam significativamente nos custos operacionais relativos à eficiência energética (consumo de combustível). Buscando conjugar o objetivo da dinâmica ferroviária aos propósitos de programação (e reprogramação) de trens, Medanic e Dorfman (2002) desenvolveram um modelo também em SED a partir do algoritmo TAS (Travel 
Advance Strategy). Essa rotina é basicamente uma disciplina de serviço que, a partir dos tempos de rota e localização dos trens da vizinhança, determina uma decisão com ótimo local para cada trem (parar ou avançar) ao aproximar-se de uma ocasião de ultrapassagem ou cruzamento.

Dentro deste cenário, os autores propuseram medir a eficiência do algoritmo em termos de dois critérios distintos: tempo e energia. Para o critério tempo, comparou-se o intervalo entre a partida do primeiro trem e a chegada do último trem para duas condições distintas. Desta forma, verificou-se a razão entre o intervalo de tempo total em condições ideais (sem cruzamentos de trens em sentidos contrários, como em linhas duplas, uma para cada sentido) e o intervalo de tempo em condições reais (ocorrendo cruzamentos, como numa linha singela), obtendo uma medida de rendimento $\eta=\Delta t_{\text {ideal }} / \Delta t$. Para o critério energia, após a aplicação do TAS, outro algoritmo promove um ajuste no cronograma ao reduzir as esperas em cruzamento através da diminuição da velocidade dos trens, mas mantendo $\eta$. Com isso, reduz-se diretamente o consumo energético que, matematicamente, é uma função convexa que depende da velocidade do trem. Os resultados mostraram-se satisfatórios com uma complexidade de implementação moderada e $\eta$ em um intervalo de $[0,95 ; 0,99]$ para uma grande variedade de problemas, atingindo os objetivos de eficiência energética previstos.

Ainda dentro do cenário de decisões de reprogramação, Afonso e Bispo (2011) desenvolveram uma rotina para despachadores (operadores de tráfego) de ferrovias de linha singela com composição peculiarmente europeia: trens de passageiros (rápidos e lentos) e trens de carga. Inserindo diferentes prioridades por tipo de trem no modelo (passageiros rápidos > passageiros lentos > carga), a rotina se inicia com uma busca por todos os possíveis conflitos a partir de uma tabela de partidas e chegadas planejada para um determinado período de tempo. Após a busca ser realizada, duas soluções são propostas: uma heurística de escolha por prioridade e mínimo atraso do trem a ser parado e um algoritmo de busca em profundidade.

É evidente que as decisões de reprogramação requerem a obtenção de soluções de forma célere. Essa situação tende a se tornar mais complicada ao passo que algumas restrições aumentam como o número de trens, número de pátios e o horizonte de tempo a simular. Este é o principal entrave para o algoritmo de busca em profundidade, que utiliza uma rotina branchand-bound para obter a solução ótima. Neste sentido, os autores realizam alguns experimentos computacionais, concluindo que para certos limites operacionais (número trens $\leq 12$ e pátios $\leq 24$, por exemplo), a busca pela otimalidade ainda vale a pena (solução ótima obtida em menos de 30 minutos). Além disso, foi possível notar que, apesar do caráter guloso da heurística, as soluções não são díspares entre ambos os métodos para a maior parte dos casos, atestando a eficácia de uma alternativa de menor custo de implementação.

Por vezes, os trabalhos para representação e otimização da programação de trens apresentam peculiaridades interessantes. Esse é o caso da ferramenta de apoio à decisão desenvolvida por Sajedinejad et al (2011) no sistema ferroviário iraniano (mesclado por linhas singelas e duplas) onde a restrição de paradas de trens para as orações muçulmanas tradicionais se juntam às demais. Essas paradas consistem em permanência de até 25 minutos em estações para as três orações diárias previstas no regulamento da autoridade ferroviária nacional. Outra importante característica desta modelagem diz respeito aos trabalhos de manutenção da via permanente que também exigem paradas de trens, devido a uma infraestrutura antiga e precária da malha.

Para resolver o problema de minimização de atraso no planejamento diário de trens, os autores propuseram uma ferramenta de SED integrada a um algoritmo genético para geração de um diagrama de cruzamentos ótimo. Este algoritmo, baseado na lei natural da evolução das espécies por seleção natural, geram os horários de partida (cromossomos) onde cada trem (gene) possui seu horário específico. A partir de cada simulação (geração), as mutações tendem a reduzir os atrasos buscando uma solução ótima verificando ao final se o 
critério de parada foi atendido. Os resultados mostraram-se satisfatórios, onde cerca de 400 gerações foram necessárias para atingir os objetivos de atraso mínimo na geração de diagramas de horizonte de 24 horas com 152 estações e 148 trens em tráfego.

Dentro do contexto nacional, vale salientar o trabalho desenvolvido por Fioroni (2008) na modelagem do sistema ferroviário da empresa MRS Logística nos cerca de 1600 $\mathrm{km}$ ao longo dos estados de Minas Gerais, Rio de Janeiro e São Paulo. O estudo foi desenvolvido em três frentes com objetivos distintos. O primeiro deles propõe resolver os problemas de conflitos de trens (ultrapassagem e cruzamento) ao longo da malha. Num segundo momento, determinar uma decisão de direcionamento ótima de carregamento para os trens de ciclo recém-descarregados no porto. Por fim, com as duas etapas anteriores consolidadas, uma análise de sensibilidade para avaliar os impactos na tonelagem por produto entregue nos portos. Para o primeiro objetivo, uma heurística de decisão local para a escolha de avançar/esperar de cada trem foi desenvolvida, ao passo que o segundo objetivo foi obtido a partir de uma otimização via programação inteira para escolha do melhor terminal e a terceira através de modificações no modelo em SED desenvolvido.

A relevância do trabalho de Fioroni (2008) tem sido atestada em outras aplicações em pesquisas recentes, a exemplo das desenvolvidas por Camargo (2010) no sistema FCAEFVM-Tubarão (Vale), Carneiro (2011) no Terminal Ferroviário de Ponta da Madeira, Guachalla (2012) no descarregamento de vagões de minério da MRS e Meireles (2010) na representação de trens de ciclo de minério na EFVM (Vale). Sendo também o direcionador da pesquisa em curso do presente artigo, alguns aspectos do desenvolvimento da heurística de decisão local para resolução de conflitos serão detalhados na próxima seção. A Tabela 1 resume as características dos trabalhos mencionados:

Tabela 1- Resumo dos trabalhos mencionados

\begin{tabular}{|c|c|c|c|}
\hline Autor(es) & Contexto & $\begin{array}{l}\text { Infraestrutura } \\
\text { Ferroviária }\end{array}$ & Método(s) \\
\hline Cheng (1998) & \multirow{4}{*}{ Internacional } & Linhas duplas & $\begin{array}{l}\text { Simulação Híbrida } \\
\text { (SED e Redes) }\end{array}$ \\
\hline Medanic e Dorfman (2002) & & Linhas singelas & SED e Heurística \\
\hline Afonso e Bispo (2011) & & Linhas singelas & $\begin{array}{c}\text { SED, Heurística e } \\
\text { Depth-First Search }\end{array}$ \\
\hline Sajedinejad (2011) & & $\begin{array}{c}\text { Linhas singelas e } \\
\text { duplas }\end{array}$ & $\begin{array}{l}\text { SED e Algoritmo } \\
\text { Genético }\end{array}$ \\
\hline Fioroni (2008) & \multirow{5}{*}{ Nacional } & $\begin{array}{c}\text { Linhas singelas e } \\
\text { duplas }\end{array}$ & $\begin{array}{l}\text { SED, Heurística e } \\
\text { Programação Inteira }\end{array}$ \\
\hline Camargo (2010) & & Linhas singelas & SED e Heurística \\
\hline Carneiro (2011) & & Terminal ferroviário & SED \\
\hline Guachalla (2012) & & Terminal ferroviário & SED \\
\hline Meireles (2010) & & $\begin{array}{c}\text { Linhas singelas e } \\
\text { duplas }\end{array}$ & SED \\
\hline
\end{tabular}

\section{MODELAGEM DA LOGÍSTICA DO MINÉRIO DE FERRO NA FIOL}

Como evidenciado anteriormente, o minério de ferro constitui-se na principal carga do empreendimento da FIOL. Desde o carregamento dos vagões no município de Caetité-BA, $536 \mathrm{~km}$ serão percorridos até a chegada no Porto Sul (Ilhéus), onde o minério será descarregado no Terminal de Uso Privativo (TUP) da Bahia Mineração (BAMIN). Os trens serão do tipo de ciclo, dedicado ao transporte de minério, entre dois terminais de carga e 
descarga definidos, realizando repetidamente o circuito: Carrega (Caetité) $\rightarrow$ Desloca $\rightarrow$ Descarrega (Porto Sul) $\rightarrow$ Desloca $\rightarrow$ Carrega (Caetité).

Durante esse percurso, uma série de conflitos pode ocorrer. A característica de cada conflito e sua respectiva resolução, dada por uma heurística de decisão local (FIORONI, 2008), serão descritas a seguir.

\subsection{Possíveis CONflito de Trens na FIOL e as SoluÇões Propostas}

As decisões de movimentação dos trens devem respeitar as condições de uma ferrovia funcionando com sinalização em bloqueio fixo (somente um trem pode ocupar cada bloco) e a anulação de travamentos na malha (vide Figura 5). Para isso, um conjunto de questionamentos encadeados deve ser realizado para cada trem diante da decisão de mover adiante ou aguardar até uma condição ser atendida. A estrutura dessa heurística pode ser observada, em resumo, na Figura 7:

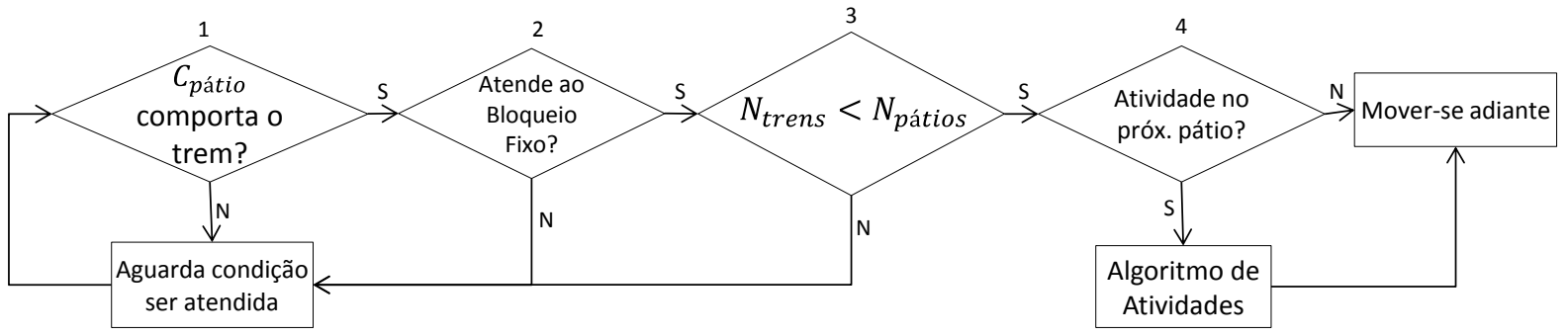

Figura 7 - Fluxograma da heurística de decisão para resolução de conflitos

A primeira decisão diz respeito à capacidade do próximo pátio ao qual o trem deve se dirigir. O pátio de cruzamento seguinte só comportará o trem caso ele esteja vazio em ambas as linhas (desviada e principal) ou se houver somente um trem no sentido contrário (dois trens no mesmo sentido não são permitidos em um mesmo ponto de cruzamento, visto que há somente duas linhas). A segunda decisão torna evidente a existência de sinalização por bloqueio fixo, não permitido que mais de um trem ocupe o mesmo bloco, além de identificar o sentido da linha ao qual o trem pretende trafegar. Deste modo, a composição avança se a próxima sessão de bloqueio estiver livre e se o segmento de linha entre pátios que contém essa sessão de bloqueio estiver sem reserva de sentido ou reservada no mesmo sentido desta composição. Na terceira, por sua vez, o trem atual verifica se no espaço compreendido entre ele mesmo e o próximo trecho reservado no sentido oposto, o número de trens no mesmo sentido (contando com ele próprio) é menor que o número de pátios de cruzamento. Este critério garante que não ocorra o travamento evidenciado na Figura 5, apresentado anteriormente. Por fim, a quarta decisão verifica se o trem realizará alguma atividade no pátio seguinte, devendo proceder de acordo com o tipo de algoritmo específico para cada atividade (abastecimento, carregamento ou descarregamento, dentre outras).

Para esclarecer melhor como a resolução destes conflitos será obtida, alguns casos serão a seguir analisados.

\subsubsection{Conflito Tipo 1 - Dois trens movendo-se em sentidos opostos}

Este é o caso mais simples, onde o primeiro trem a acessar o pátio deverá se deslocar ao longo da linha enquanto o outro aguarda a sua passagem. Essa premissa é válida para o caso de todos os trens na malha possuirem a mesma prioridade. Pode-se notar na Figura 8 que o trem A, ao alcançar o pátio 2, executa o algoritmo e identifica a presença do trem B no pátio logo adiante (pátio 3), devendo aguardar sua passagem para prosseguir viagem: 
a)

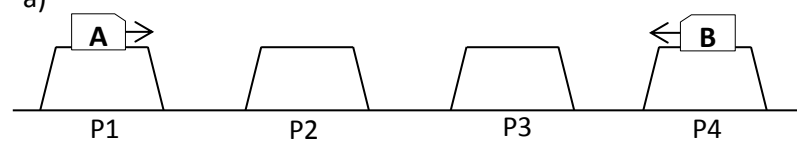

c)

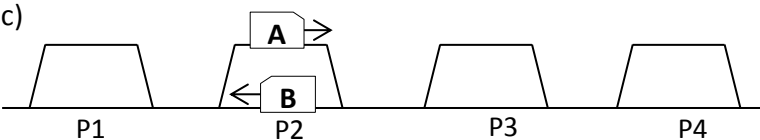

b)

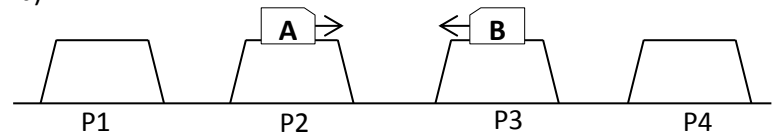

d)

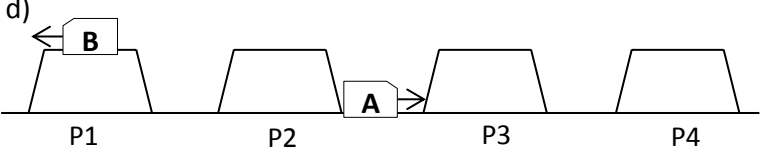

Figura 8 - Resolução do conflito Tipo 1

\subsubsection{Conflito Tipo 2 - Dois trens em um mesmo sentido e outro no sentido inverso}

A mesma análise do caso de conflito anterior pode ser desenvolvida para o caso de 3 trens com a situação demonstrada na Figura 9:

a)

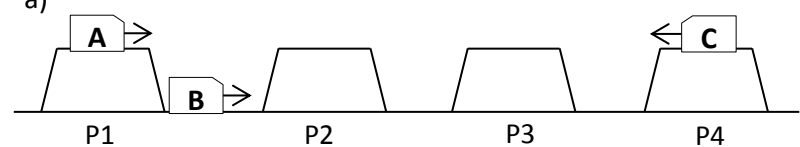

c)

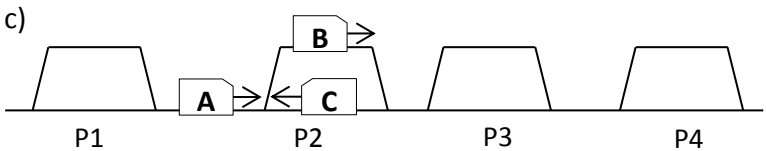

b)
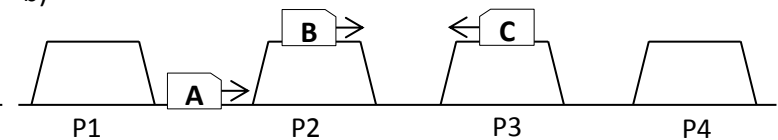

d)

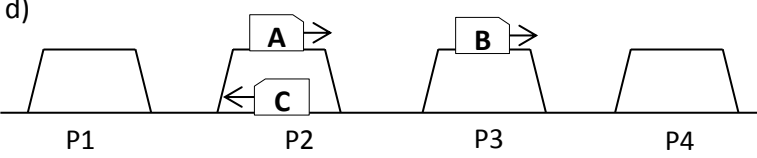

Figura 9 - Resolução do conflito Tipo 2

\subsubsection{Conflito Tipo 3 - Dois trens em um mesmo sentido e outros dois no sentido inverso}

Nesse caso há um aumento de complexidade, uma vez que o travamento apresentado na análise da Figura 5 se torna iminente. A Figura 10 ilustra como esse processo se desenvolve:

a)

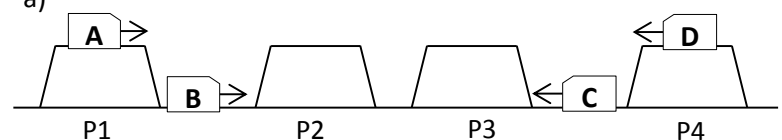

c)

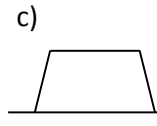

P1

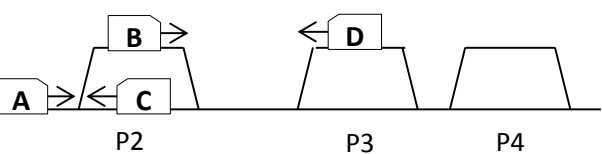

b)

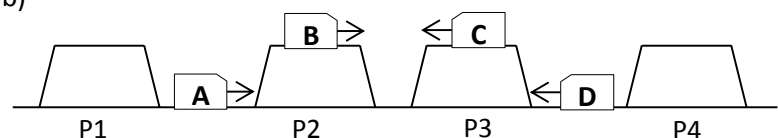

d)

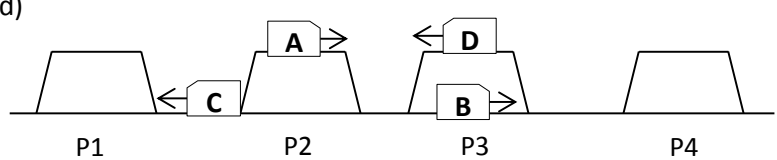

Figura 10 - Resolução do conflito Tipo 3

Observa-se na Figura 10c que o trem D não atende à terceira condição. Isto ocorre porque o número de trens no mesmo sentido entre o pátio em que ele se encontra (P3) até o próximo pátio reservado no sentido contrário (P2) não é menor que o número de pátios (de fato, $N_{\text {trens }}=N_{\text {pátios }}=2$ ). Desta forma, deve aguardar o trem B fazer o seu deslocamento, liberando espaço no pátio 2 para o trem A, o que ocasiona um caminho livre para este último, não permitindo o travamento do fluxo.

Comprovando conceitualmente que a heurística corresponde às necessidades de resolução de conflitos locais de trens, é necessário observar se essa estrutura funcionará de forma válida no ambiente da simulação de eventos discretos realizada dentro do software de simulação Arena ${ }^{\circledR}$. A esse processo de correspondência entre o modelo conceitual e o operacional (computacional) dá-se o nome de verificação. 


\subsection{Processo de VerificaÇão da HeUrística No Modelo de SED do ARENA ${ }^{\circledR}$}

O Arena ${ }^{\circledR}$ é uma ferramenta computacional para simulação de eventos discretos que converte o modelo conceitual e informações estatísticas sobre o processo (dados coletados e tratados) em um modelo computacional de um projeto de simulação. Cada bloco representado no fluxograma tem uma função específica que é identificada com um comando na linguagem de programação SIMAN, que descreve em forma de algoritmo o processo contido no modelo conceitual.

As diversas ocasiões foram testadas dentro do modelo considerando-se uma geração de trens em uma estação de carregamento percorrendo 3 pátios de cruzamento até alcançar a estação de descarregamento, como pode ser visto na Figura 11, extraída da animação no Arena ${ }^{\circledR}$. Cada trem no programa representa uma "entidade", que são os recursos a serem transformados qualquer tipo de sistema a ser simulado.

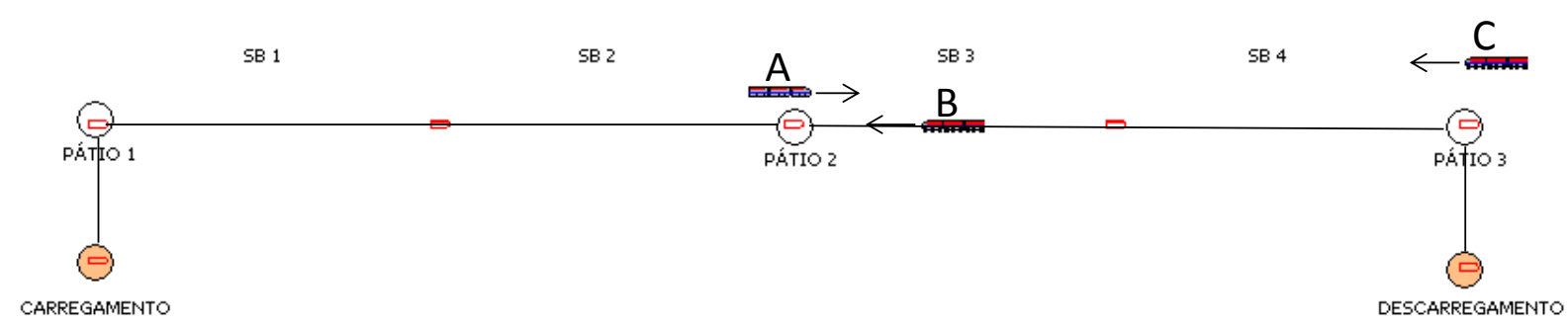

Figura 11 - Reprodução da animação do Arena ${ }^{\circledR}$ com a situação de conflitos

No cenário acima os trens $\mathrm{A}, \mathrm{B}$ e $\mathrm{C}$ são criados na estação de carregamento e desenvolvem o seguinte itinerário: Carregamento $\rightarrow$ Pátio $1 \rightarrow$ SB1 $\rightarrow$ SB2 $\rightarrow$ Pátio $2 \rightarrow$ SB3 $\rightarrow \mathrm{SB} 4 \rightarrow$ Descarregamento. Ao fim desse percurso, realizam o caminho inverso formando um ciclo nesse pequeno trecho de malha que se repete sucessivas vezes até o fim da simulação. Logo acima pode-se observar o trem $\mathrm{C}$ aguardando em fila devido ao não atendimento da condição do terceiro critério de decisão $\left(N_{\text {trens }}<N_{\text {pátios }}\right)$ e o trem A aguardando devido ao não atendimento do segundo critério (SB à frente ocupada e reservada com sentido inverso). $\mathrm{O}$ trem $\mathrm{B}$, por sua vez, está permitido seguir até o Pátio 2, uma vez que este só tem uma linha ocupada (com o trem A). É importante frizar que a resolução também atende aos casos em que o primeiro critério não é atendido (pátio não permitir entrada do trem), além do critério de atividades (como pôde ser observado com a saída e entrada de trens das regiões de carregamento e descarregamento).

\subsection{A REPRESENTAÇÃo COMPLETA DO SISTEMA FIOL NO ARENA ${ }^{\circledR}$}

A etapa de representação do modelo dentro do escopo definido (Caetité-BA a IlhéusBA) consistiu na inserção da quantidade de trens prevista para circular entre as regiões de carregamento e descarregamento passando pelos 19 pátios de cruzamento. Logo após, o modelo foi alimentado com os dados de tempo de viagem e licenciamento de trens (BRASIL, 2010), além das durações de atividades como carregamento e descarregamento fornecidas pelo futuro operador de minério de ferro da malha. A animação do modelo computacional pode ser observada na Figura 12: 


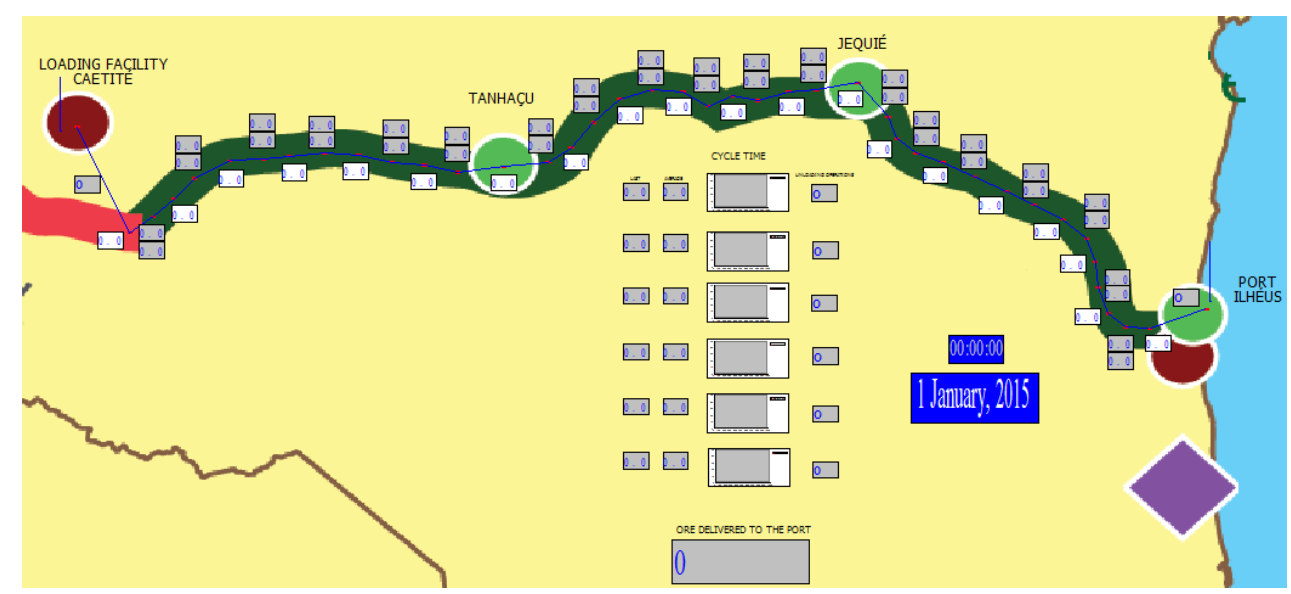

Figura 12 - Cenário de animação do modelo completo desenvolvido no Arena ${ }^{\circledR}$

\section{RESULTADOS}

\subsection{VAlidação do Modelo}

Um bom projeto de simulação requer que o modelo construído possa representar satisfatoriamente o sistema em estudo. Para tanto, um processo chamado validação deve ser conduzido, identificado se os valores de algumas variáveis de saída de interesse e as interações entre as entidades e recursos correspondem com a lógica esperada de funcionamento.

A consistência do modelo pôde ser provada com a observação de duas medidas anteriormente mencionadas: tempo de ciclo dos trens de minério e quantidade de minério entregue no porto, que se encontram se disponíveis nos estudos de impacto ambiental do Porto Sul (BAHIA, 2011). Vale salientar que todos os dados inseridos no modelo são determinísticos, da forma como foram obtidos nos relatórios de projeto. A simulação com uma única replicação de 365 dias no modelo resultou em um desvio máximo de $1 \%$ em relação ao ciclo planejado do trem de minério de ferro (38h) e um desvio inferior a $6 \%$ em relação à quantidade total de minério a ser entregue no porto anualmente (20 milhões de toneladas por ano). Deste modo, pode-se atestar a razoabilidade da consistência do cenário básico modelado com o previsto pelos estudos de planejamento da ferrovia.

\subsection{DESEMPENHO DE TRÁFEGO}

O cenário modelado tem como referência o projeto da mineradora que possui zona de carregamento em Caetité e propõe com 6 composições ferroviárias (cada composição compreende o conjunto de 2 locomotivas tracionando 140 vagões, formando um trem) transportando cada uma 15.540 toneladas. Como o ciclo (carrega $\rightarrow$ transporta $\rightarrow$ descarrega)é realizado em 38 horas, uma média de 4 composições descarregam no porto diariamente.

Espera-se que os conflitos entre os trens trafegando em sentidos contrários em linhas singelas produzam filas nos pátios de cruzamento e regiões de carregamento/descarregamento. Para verificar o impacto desses conflitos no tempo de espera em filas (e, logo, no tempo de ciclo total), um experimento computacional foi conduzido no Arena ${ }^{\circledR}$ a partir de uma replicação de 365 dias e seus resultados encontram-se registrados na Tabela 2. As variáveis de saída observadas foram o tempo médio de espera em fila de toda a 
malha, o tempo médio de ciclo, o número de ciclos realizados ao longo do ano, a quantidade de minério de ferro entregue no porto em toneladas e a quantidade de minério em toneladas por trem operando na malha anualmente.

Tabela 2- Desempenho de tráfego com aumento do número de trens de MF

\begin{tabular}{|c|c|c|c|c|c|}
\hline \# Trens & $\boldsymbol{T F}_{\text {méd }}(\boldsymbol{h})$ & $\boldsymbol{T} \boldsymbol{C}_{\text {méd }}(\boldsymbol{h})$ & \# Ciclos & MF Porto (ton) & MF/Trem (ton/un.ano) \\
\hline $\mathbf{6}$ & 13,67 & 38,51 & 227 & 21.181 .020 & 3.530 .170 \\
\hline $\mathbf{7}$ & 14,20 & 39,05 & 224 & 24.351 .180 & 3.478 .740 \\
\hline $\mathbf{8}$ & 15,30 & 39,81 & 220 & 27.303 .780 & 3.412 .973 \\
\hline $\mathbf{9}$ & 16,00 & 40,46 & 216 & 30.209 .760 & 3.356 .640 \\
\hline $\mathbf{1 0}$ & 17,95 & 43,18 & 202 & 31.452 .960 & 3.145 .296 \\
\hline $\mathbf{1 1}$ & 25,04 & 47,48 & 184 & 31.468 .500 & 2.860 .773 \\
\hline $\mathbf{1 2}$ & 26,76 & 51,77 & 169 & 31.468 .500 & 2.622 .375 \\
\hline $\mathbf{1 3}$ & 28,12 & 56,06 & 156 & 31.484 .040 & 2.421 .849 \\
\hline $\mathbf{1 4}$ & 30,04 & 60,34 & 145 & 31.515 .120 & 2.251 .080 \\
\hline $\mathbf{1 5}$ & 30,12 & 64,63 & 135 & 31.515 .120 & 2.101 .008 \\
\hline
\end{tabular}

Legenda: $\mathrm{TF}=$ Tempo de espera em fila, $\mathrm{TC}=$ Tempo de ciclo e MF = minério de ferro

Com base na Tabela 2, pode-se evidenciar que ao passo que aumenta-se o número de composições trafegando no sistema, o tempo de espera em filas eleva-se sensivelmente. Uma observação interessante é que o crescimento marginal mais significativo ocorre de 10 para 11 composições alterando-se o tempo de espera em filas médio em cerca de 8 horas. Isso ocorreu devido ao aumento considerável da formação de filas em regiões de carregamento e descarregamento a partir desse ponto, que consomem muito mais horas de espera em relação aos pátios de cruzamento. Para esclarecer melhor, um trem esperando em cruzamento não aguarda mais que 1 hora (tempo máximo de tráfego entre dois pátios), ao passo que nas regiões de carregamento ou descarregamento, a operação completa não ocorre em menos de 4 horas.

Como consequência do aumento na espera em filas, o tempo de ciclo médio foi afetado, reduzindo, assim, o número de ciclos realizados por ano por cada composição na malha. Não obstante esse aumento no tempo de ciclo que leva os trens a entregarem o minério no porto em mais tempo, o aumento do número desses trens na malha consegue compensar esse fator, entregando mais minério no porto a cada incremento unitário. Apesar disso, percebe-se um rendimento decrescente de escala (quantidade de minério de ferro por trem), que tende a estabilizar o montante anual entregue no porto em aproximadamente 31,5 milhões de toneladas a partir de 10 composições. Esses comportamentos podem ser identificados na Figura 13. 

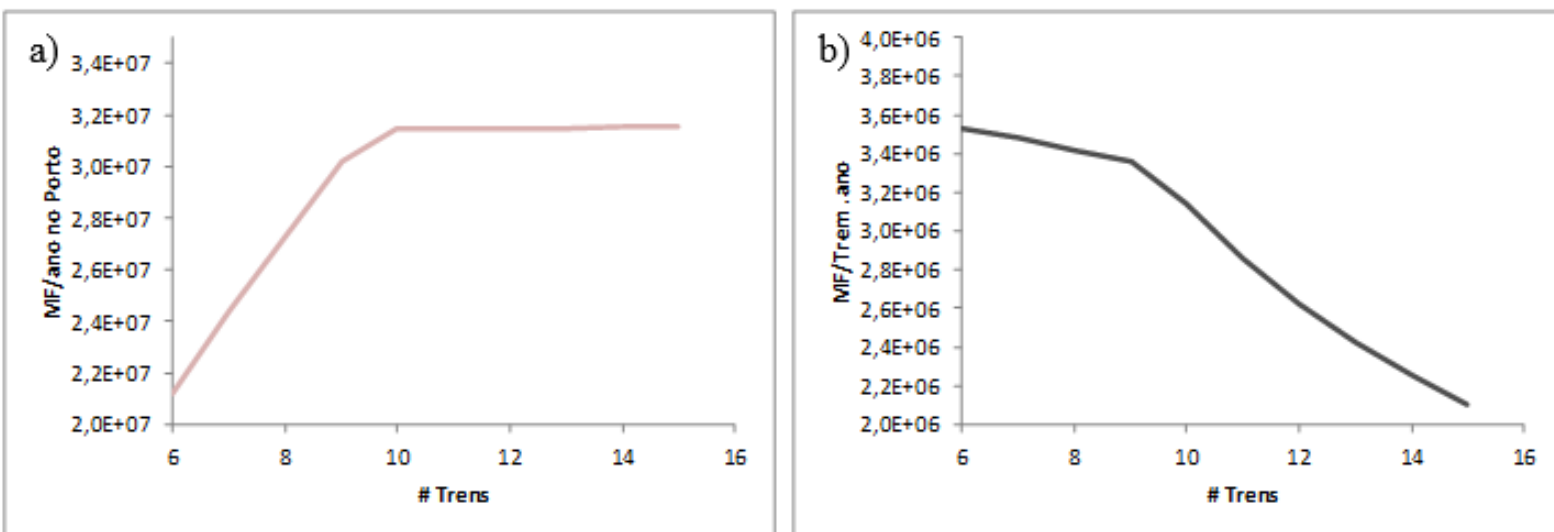

Figura 13 - Quantidade de minério entregue no porto (a) e desempenho do transporte de minério/trem (b).

\section{CONCLUSÃO E DESAFIOS FUTUROS}

Os trabalhos em modelagem ferroviária envolvem grandes desafios devido à característica morfológica peculiar destes sistemas. Para contornar esses desafios e construir uma representação satisfatória de uma malha, é necessário que as regras de tráfego sejam inseridas de forma correta. Isso acontece com o emprego de algoritmos que reproduzem o comportamento cotidiano dos centros de comando operacional das operadoras ferroviárias, que buscam resolver os conflitos para atender os objetivos de seus clientes. A execução destas regras dentro de um modelo de simulação de eventos discretos permite que o problema seja tratado de forma dinâmica, representando o comportamento de um sistema ferroviário real de acordo com um horizonte de tempo desejado.

Sustentado nessas premissas, este trabalho desenvolveu um modelo da Ferrovia de Integração Oeste Leste, um importante vetor de desenvolvimento para o Centro Oeste e o Nordeste brasileiro. Para atestar a validade deste modelo, variáveis de interesse importantes foram comparadas entre a simulação executada e os valores de projeto, além de verificações do projeto conceitual de circulação de trens no modelo computacional. Os resultados se mostraram satisfatórios, apresentando baixa variação percentual na confrontação dos valores dessas variáveis.

Sokolowski e Banks (2009) garantem que as análises "what-if" ("E se") no desenho de um sistema são um dos principais benefícios para o tomador de decisões num estudo de simulação. Com a entrada de novos operadores no sistema pouco tempo depois do início do tráfego na FIOL, as restrições de capacidades se tornarão prementes. Imbuído nesse propósito e motivado pelo recente cenário negativo do mercado mundial do minério de ferro, trabalhos futuros a partir do modelo já desenvolvido terão o principal desafio de investigar intervenções proveitosas para melhoria do sistema. Espera-se, com os procedimentos e análises técnicas contidas no presente trabalho, contribuir para a consolidação da FIOL.

\section{REFERÊNCIAS BIBLIOGRÁFICAS}

[1] AFONSO, P.A. e BISPO, C.F. Railway Traffic Management: Meet and Pass Problem. Journal of System and Management Sciences. Vol 1., n. 1, pp. 1-26, 2011.

[2] BAHIA (Estado). Secretaria de Infraestrutura. Estudo de Impacto Ambiental Porto Sul, Tomo I: Caracterização do empreendimento. Salvador, 2011, 460 p. 
[3] BANKS, J. Handbook of Simulation: Principles, Methodology, Advances, Applications and Practice, $1^{\mathrm{a}}$ edição, Ed. Jerry Banks, New York: John Wiley and Sons. 1998.

[4] BRASIL. Ministério dos Transportes. VALEC Engenharia, Construções e Ferrovias. Volume I - Estudo Operacional da Ferrovia de Integração Oeste Leste EF-334. 2010. Disponível em: <http://bit.ly/1AxJLid>. Acesso em: 12/12/2014.

[5] CAMARGO, P. V. Análise de um Sistema de Transporte Ferroviário de Granéis Agrícolas através de uma Abordagem Integrada de Simulação-Otimização. 125 p. Dissertação (Mestrado em Engenharia de Transportes), Poli-USP, São Paulo, 2010.

[6] CARNEIRO, F.M. Simulação do Circuito de Minério do Terminal Ferroviário de Ponta da Madeira (TFPM). 57 P. Monografia (Especialização em Transporte Ferroviário de Carga), IME, 2008.

[7] CHENG, Y. Hybrid Simulation for Resolving Conflicts in Train Traffic Rescheduling. Computers in Industry. 35, pp. 233-246, 1998.

[8] CONFEDERAÇÃO NACIONAL DO TRANSPORTE-CNT. Atlas do Transporte. Disponível em: <http://bit.ly/1ugCVLI>. 2006. Acesso em: 20/11/2013.

[9] CONFEDERAÇÃO NACIONAL DO TRANSPORTE-CNT. Plano CNT de Transporte e Logística 2014. Disponível em: < http://bit.ly/1v2UycS >. 2014. Acesso em: $15 / 12 / 2014$.

[10] GUACHALLA, W.F. Avaliação dos Reflexos da Operação do Virador de Vagões em Produção e na Fila de Trens para Descarga de Produtos. 105 p. Dissertação (Mestrado em Geotecnia e Transportes), UFMG, Belo Horizonte, 2012.

[11] FIORONI, M.M.Simulação em Ciclo Fechado de Malhas Ferroviárias e suas Aplicações no Brasil: Avaliação de Alternativas para o Direcionamento de Composições. 216 p. Tese (Doutorado em Eng. Naval e Oceânica), Poli-USP, São Paulo, 2008.

[12] INDEX MUNDI. Iron Ore Monthly Price - US Dollars per Dry Metric Ton. Disponível em: <http://bit.ly/1xeDw1O>. 2015. Acesso em 02/02/2015.

[13] MEIRELES, R.P.L. Modelagem e Simulação da Malha Ferroviária em Circuito Fechado da Estrada de Ferro Vitória a Minas. 218 p. Dissertação (Mestrado em Engenharia Civil), UFES, Vitória, 2010.

[14] MEDANIC, J. e DORFMAN, M.J. Efficient Scheduling of Traffic on a Railway Line. Journal of Optimization Theory and Applications. Vol. 115, n. 3, pp. 587-602, 2002.

[15] NG, Jasmine. Goldman Calls End to Iron Age after "Dramatic" Drop in Ore Price. Bloomberg. set/2014. Disponível em: < http://bloom.bg/1xuPfmB >. Acesso em $30 / 09 / 2014$

[16] SAJEDINEJAD, A., MARDANI, S., HASANNAYEB, E., MOHAMMADI, S. A., KABIRIAN, A. SIMRAIL: Simulation Based Optimization Software for Scheduling Railway Network. Proceedings of the 2011 Winter Simulation Conference. pp. 37353746, 2011.

[17] SOKOLOWSKI, J. A. e BANKS, C. M., Principles of Modeling and Simulation: a Multidisciplinary Approach, Hoboken: John Wiley and Sons, 2009.

[18] WORLD ECONOMIC FORUM, E. The Global Competitiveness Report 2013-2014. Geneva., 2013. 